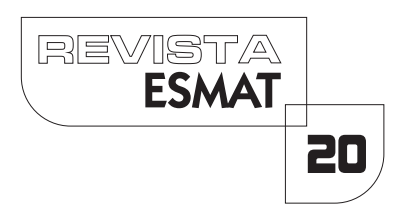

\title{
A DELAÇÃO PREMIADA COMO NOVA TECNOLOGIA DO PODER PUNITIVO NO ENFRENTAMENTO À CRIMINALIDADE ORGANIZADA
}

DELATION AWARDED AS A NEW TECHNOLOGY OF THE PUNITIVE POWER IN COPING WITH THE ORGANIZED CRIME

BARTIRA MACEDO DE MIRANDA ${ }^{1}$
JÚLIA FAIPHER MORENA V. DA SILVA DORNELAS ${ }^{2}$

\section{RESUMO}

O presente artigo discute como a Delação Premiada, inserida no contexto de expansão dos espaços de consenso no Processo Penal, apresenta-se como uma nova tecnologia do poder punitivo a pretexto de enfrentar a criminalidade organizada. O ponto de partida da abordagem é a concentração de discursos punitivos no Brasil, bem como a colonização da Política Criminal pela racionalidade neoliberal. Descreve-se como a expansão do Direito Penal e o eficientismo foram determinantes para a importação de mecanismos negociais, dentre os quais a Delação Premiada, no Brasil. Observa-se como a espetacularização do processo penal, combinada com o uso exacerbado da Delação Premiada, pode catalisar a mitigação do Processo Penal Democrático.

PALAVRAS-CHAVE : Processo Penal. Justiça Criminal Negocial. Delação Premiada. Poder Punitivo. Retrocesso Democrático.

\begin{abstract}
This article discusses how the Plea Bargaining, inserted in the context of expanding the spaces of consensus in the Criminal Procedure, presents itself as a new technology of punitive power in the fight against organized crime. The starting point of the approach is the concentration of punitive discourses in Brazil, as well as the colonization of Criminal Policy by neoliberal rationality. It is described how the expansion of Criminal Law and efficiency were
\end{abstract}

\footnotetext{
1 Doutora em História da Ciência pela PUC-SP. Diretora da Faculdade de Direito da UFG. Professora do Programa de Pós-Graduação em Direito e Políticas Públicas da UFG (PPGDP). Coordenadora do Curso de Especialização em Direito e Penal e Direito Processual Penal da FD/UFG. Conselheira Seccional da Ordem dos Advogados do Brasil - Secção Goiás.

2 Advogada Criminalista. Mestranda em Direito e Políticas Públicas, pela UFG. Pós-Graduanda em Direito Penal e Direito Processual Penal, pela UFG.
} 
determinants for the importation of negotiation mechanisms, including the Plea Bargaining, by Brazil. It is observed how the spectacularization of the criminal process combined with the exacerbated use of the Plea Bargaining can catalyze the quenching of the Democratic Criminal Process.

KEYWORDS: Criminal Procedure. Bargained Criminal Justice. Plea Bargaining. Punitive Power. Democratic Backsliding.

\section{INTRODUÇÃO}

O problema fundamental do direito penal e do processo penal sempre foi o de impor limites ao poder punitivo. Mas, como todo poder, engenhoso e artificioso, o poder punitivo sempre se transforma por meio da renovação de seus discursos e tecnologias, escapando às regras que o tentam limitar.

Zaffaroni demonstra que o poder punitivo, desde que inventado, por volta do século XIII, a sua estrutura discursiva é a mesma, mudando apenas o seu conteúdo. É engraçado que o poder punitivo jamais resolveu problema algum, mas ai de quem se atreva a dizer que ele não funciona. Há mais de 800 anos insistimos no mesmo remédio e ninguém parece se indignar que ele não funciona (salvo os criminologistas críticos!). É como um remédio com o qual o paciente sempre morre no final e ninguém se pergunta por um tratamento melhor.

Agora, pensando em eficiência, alguém tem a ideia de matar logo o paciente, economizando com o remédio. Eis o que ocorre na nova tecnologia do poder punitivo no século XXI: resolveram matar o direito penal e o processo penal, substituindo-os pelos acordos penais, dos quais a transação penal, a delação premiada e o acordo de não persecução penal, inseridos no Código de Processo Penal pela Lei n 13.964, de 2019 (pacote anticrime), são os maiores exemplos.

Este artigo se propõe a refletir sobre a delação premiada como nova tecnologia do poder punitivo no enfrentamento à criminalidade organizada. Em seguida, pontua-se como a espetacularização do processo penal conjugada com o uso exacerbado de delações premiadas catalisam a mitigação do processo penal democrático. 
ESMAT BARTIRA MACEDO DE MIRANDA / JÚLIA FAIPHER MORENA V. DA SILVA DORNELAS

\section{CONCENTRAÇÃO DE DISCURSOS PUNITIVOS NO BRASIL}

Vários criminólogos já chamaram a atenção para um aspecto crescentemente punitivo, repressivo e discriminatório que tem revestido as políticas de segurança e as estratégias penais a ela associadas.

Wacquant, por exemplo, identifica a substituição do Estado Social por um Estado Penal e evidencia a "escalada do neoliberalismo como projeto ideológico e prática de governo que determina a submissão ao livre mercado e a celebração da responsabilidade individual em todos os domínios" e o desenvolvimento de políticas de segurança ativas e punitivas centradas nas fissuras e nas margens da nova ordem econômica e moral. Nota-se uma mudança nos discursos em relação ao crime para criminalizar de forma sistemática e cultivar o medo: "não foi tanto a criminalidade que mudou no momento atual, mas sim o olhar que a sociedade dirige para certas perturbações da via pública, para as populações despossuídas e desonradas" (WACQUANT, 2007).

Jock Young aponta um movimento de transição de um paradigma includente a um paradigma excludente, que envolveu processos de desintegração, tanto na esfera da comunidade (aumento do individualismo) como na esfera do trabalho (transformação do mercado de trabalho). Para ele, o período de transição entre a modernidade e a modernidade recente, com suas singularidades, acentuou drasticamente a dialética da exclusão; e as mudanças na esfera de produção e consumo, com seu desenvolvimento e reinterpretação pelos atores envolvidos, tiveram efeitos sobre as causas da criminalidade e do desvio e sobre as reações contra eles (YOUNG, 2002).

David Garland denuncia o crescimento de uma "cultura do controle", ao repensar o presente das maneiras de controlar o crime e fazer justiça, que são os sinais de uma perturbadora subversão do padrão histórico predominante na quase totalidade do século XX: “os processos modernizantes que, há tão pouco tempo, pareciam sedimentados nesse domínio - acima de todas as tendências de longo prazo que apontavam para a 'racionalização' e para a 'civilização' - agora aparentam ter engatado a marcha à ré” (GARLAND, 2008).

O criminólogo descreve ainda os sinais dessa mudança no controle e justiça criminais: o declínio do ideal de reabilitação; desaparecimento gradual da ratio correcional e previdenciária da intervenção no sistema penal; da reduzida ênfase na reabilitação como objetivo das instituições penais; o ressurgimento de sanções retributivas e da justiça repressiva; mudanças no tom emocional da política criminal, o retorno da vítima; a ênfase na 
necessidade de segurança, uma corrente politizada e populista das políticas penais; a transformação do pensamento criminológico; expansão da infraestrutura da prevenção do crime e da segurança da comunidade, uma perpétua situação de crise etc. (GARLAND, 2008).

A sociedade punitiva e excludente, marcada por estratégias penais que olham para trás, se globalizou (BAUMAN, 1999). O discurso da eficiência ganha eco na mesma proporção em que se desconsideram as regras mais comezinhas do processo penal garantidor de direitos. As políticas criminais de racionalidade neoliberal ganharam dimensão transnacional e encontraram terreno fértil nos países periféricos nos quais provocaram até mesmo os efeitos mais arrasadores:

\begin{abstract}
O estabelecimento de um discurso criminal transnacional inspirado nas diretrizes repressivas ditadas, basicamente, pela matriz norte-americana, reveste-se de especial vigor em países periféricos como o nosso, institucionalizando-se, com evidência, na legislação penal. Esta, produzida em níveis vertiginosos, presta-se a atender aos reclames por punição, segundo uma falaciosa retórica de intransigência alardeada pela mídia e cegamente incorporada pelo senso comum (CARVALHO, 2009).
\end{abstract}

No Brasil, por exemplo, onde historicamente se consolidou uma estrutura social hierárquica, que atribui diferentes graus de cidadania e civilização aos diferentes segmentos sociais, os discursos punitivos encontraram especial respaldo e tiveram ao seu dispor práticas inquisitoriais que se distribuem da polícia ao judiciário. Desde o Império, tivemos regras penais típicas de um País civilizado, as quais, entretanto, conviviam com a nossa realidade escravocrata, sem embaraços ou vexames, porque aqui a igualdade (garantida na lei) sempre foi para os iguais, não para os "desiguais". Entendedores entenderão que, aqui, a igualdade sempre foi garantida na lei, mas jamais garantida por lei.

Natália Oliveira pontua ainda que esse discurso criminal comum, propiciado pelo processo globalizatório e pautado por diretrizes estadunidenses, "fez com que o Direito Penal se preocupasse, precipuamente, com as questões afetas à lavagem de dinheiro, crime organizado e ao tráfico internacional de drogas", que, coincidentemente, ou não, são modalidades criminosas em que admitimos a delação premiada (CARVALHO, 2009).

Embora o discurso harmônico no sentido de que, em um Estado Democrático de Direito, a Constituição é quem proporciona validade ao ordenamento jurídico e ao Direito Penal; portanto, no seu aspecto normativo e interpretativo, deve estar em concordância e harmonia com a norma constitucional, de modo que sua formatação e aplicação devem respeitar uma série de princípios e exigências explícitas ou implícitas na Lei Fundamental, pois a transição democrática brasileira ainda tem encontrado enorme dificuldade em inserir a 
atuação penal nesse paradigma ${ }^{3}$. Como diz Vera Malaguti, "é como se uma cultura punitiva se metamorfoseasse indefinidamente" (BATISTA, 2011).

A difusão do medo e da experiência com a criminalidade propagandeada pela mídia faz com que a sanha punitiva se espalhe por todos os setores sociais, que passam a reclamar soluções a qualquer preço em nome da pacificação social. Num cenário assim, o processo penal democrático, que tem a finalidade de impor limites ao exercício do poder de punir estabelecendo regras que devem ser absolutamente observadas para uma aplicação concreta legítima da pena, bem como os direitos humanos, representam um problema, por serem vistos como obstáculo à tão idealizada paz.

É nesse cenário de "exceção" estrategicamente construído pelos donos do poder e alardeado pela mídia, que se proliferam legislações penais e processuais penais repressivas, como a institucionalização da delação premiada:

É, então, no contexto desse desenfreado processo de produção legislativa penal, permeado por enunciados repressivos emanados da ideologia da defesa social, da doutrina da segurança nacional e, ainda, das vetustas teorias acerca do inimigo do direito penal, que se opera a inserção da delação premiada no ordenamento jurídico brasileiro (...) verdadeiro produto de uma engenhosa perene e funcional política criminal pautada na concentração de discursos punitivos (CARVALHO, 2009).

\section{DELAÇÃO PREMIADA COMO "NOVA" TECNOLOGIA DO PODER PUNITIVO}

Além do exame causal explicativo do crime e do criminoso, a criminologia interpreta os mecanismos estatais de prevenção e repressão ao crime. Dada a diversidade de finalidades políticas que podem moldar os institutos penais e processuais penais adotados pelo Estado, o saber da criminologia exerce "importante papel legitimador das estratégias de controle social empreendidas pelas classes dominantes" (CARVALHO, 2009) .

Ressaltando o impacto das teorias criminológicas sobre as políticas criminais, Vera Malaguti afirma:

É por isso que todas as definições da criminologia são atos discursivos, atos de poder com efeitos concretos, não são neutros: dos objetivos aos métodos, dos paradigmas às políticas criminais. Aqui reside o enigma central da questão criminal. Talvez seja essa a lição principal do inspirador livro de Pavarini: para entender o objeto da criminologia, temos de entender a demanda por ordem de nossa formação econômica e social. A criminologia se relaciona com a luta pelo poder pela necessidade de ordem. A marcha do capital e a construção do grande Ocidente colonizador do mundo e empreendedor da barbárie precisaram da operacionalização

\footnotetext{
3“Faz-se, no Brasil dos tempos presentes, o discurso do Direito Penal de intervenção mínima, mas não há nenhuma correspondência entre esse discurso e a realidade legislativa." (FRANCO, Alberto Silva. Prefácio. In: ZAFFARONI, Eugênio Raúl. Manual de direito penal brasileiro: parte geral / Eugênio Raúl Zaffaroni, José Henrique Pierangeli. São Paulo: Editora Revista dos Tribunais, 1997. p. 12)
} 
do poder punitivo para assegurar uma densa necessidade de ordem. (BATISTA, 2011).

Nessa ótica, devemos compreender que os institutos penais e processuais penais se prestam a atender as estratégias públicas de política criminal, e são, em regra, justificados pelo saber criminológico, ou seja, por produção de discursos justificadores.

As técnicas emergenciais, a expansão da justiça criminal negocial, o encarceramento em massa, a aceleração processual, enfim, toda estratégia de política criminal estará amparada por algum saber, e para que se possa se exercê-la, o poder punitivo precisa se legitimar.

Conforme Zaffaroni, "chamamos sistema penal ao controle social punitivo institucionalizado, que na prática abarca desde que se detecta ou supõe detectar-se uma suspeita de delito até que se impõe e executa uma pena, pressupondo uma atividade normativa que cria a lei que institucionaliza o procedimento, a atuação dos funcionários e define os casos e condições para esta atuação" (ZAFFARONI, 1997).

Bem resume Marcelo Semer:

O poder punitivo é bruto, atavicamente expansivo e socialmente verticalizador. Nenhum outro meio de controle social provoca tanta violência a pretexto de combatê-la. Nenhum controle mantém-se em crescimento de uma forma tão persistente, a despeito da imensidão dos efeitos colaterais produzidos. (SEMER, 2014).

Mas, para que se possa exercer, o poder punitivo precisa se legitimar.

"A arte de punir deve repousar sobre toda uma tecnologia da representação" (FOUCAULT, 2013). Para que no século XVIII fosse introduzida uma nova tecnologia punitiva consoante aos interesses da sociedade na época, qual seja, a prisão, foi preciso um deslocamento da tecnologia da representação da vingança do soberano para a ideia de defesa da sociedade (BATISTA, 2011).

A atuação do sistema penal se dá pela cadeia de formulações teóricas e/ou ideológicas, que objetivam justificar sua atuação ou esconder suas intenções reais (SANTOS, 2009). O poder encontra o saber que lhe sustentará e reproduzirá as ideologias ${ }^{4}$ necessárias ao seu funcionamento. Por isso, o poder punitivo, com características repressoras e autoritárias, tem se legitimado em nome da defesa social (SANTOS, 2015).

\footnotetext{
4“'O termo 'ideologia' em um significado positivo (conforme o uso de Karl Mannheim) se refere aos ideais ou programas de ação; em um significado negativo (conforme o uso de Marx), se refere à falsa consciência, que legitima instituições sociais atribuindo-lhes funções diversas das realmente exercidas. Usamos o termo, aqui e no prosseguimento do curso, neste segundo sentido, com referência, em particular, à ideologia penalista, identificada como ideologia da defesa social." (BARATTA, Alessandro. Criminologia Crítica e Crítica do Direito Penal: introdução à sociologia do direito penal / Alessandro Baratta; tradução Juarez Cirino dos Santos. Rio de Janeiro: Editora Revan: Instituto Carioca de Criminologia, 6a edição, outubro de 2011. $1^{\text {a }}$ reimpressão, março de 2013. Notas. p. 240.)
} 
A defesa social está, pois, no epicentro das ideologias que definem as concepções e as finalidades do direito penal, do processo penal e do sistema de justiça criminal, especialmente nas concepções mais autoritárias e repressivas, que ainda caracterizam a atuação do sistema de justiça criminal e segurança pública. (SANTOS, 2015)

É em nome da defesa social que, tradicionalmente, são adotadas políticas de exacerbação e ampliação dos meios de combate à criminalidade:

\begin{abstract}
Nossos governantes utilizam o Direito Penal como panaceia de todos os males (direito penal simbólico), defendem graves transgressões de direitos fundamentais e ameaçam bens jurídicos constitucionalmente protegidos, infundem medo, revoltam e ao mesmo tempo fascinam uma desavisada massa carente e desinformada. Enfim, usam arbitrária e simbolicamente o Direito Penal para dar satisfação à população e, aparentemente apresentar soluções imediatas e eficazes ao problema da segurança e da criminalidade. (BITENCOURT; BUSATO, 2014)
\end{abstract}

Nesse cenário de expansão do Direito Penal, a "sede de punir” orquestra no âmbito do direito penal material que sustentemos um Direito Penal funcional, que nos expõe a retrocessos autoritários ${ }^{5}$, bem a gosto de um Direito Penal máximo, e, na área processual, na “'abreviação', redução, simplificação e remoção de obstáculos formais que, eventualmente, possam dificultar uma imediata e funcional resposta penal" (BITENCOURT; BUSATO, 2014).

Foi para defender a sociedade do "demônio" da criminalidade pós-moderna que tipificamos materialmente a criminalidade organizada e, sucumbindo aos influxos internacionais, importamos a delação premiada ${ }^{67}$.

\footnotetext{
5“A ânsia por segurança a qualquer custo, legitimadora das novas técnicas de controle e vigilância e, por conseguinte, da expansão do poder punitivo, vem permitindo, com insidiosa sutileza, a consagração de um autêntico Estado Totalitário sob a veste enrustida de Estado Democrático" (CARVALHO, Natália Oliveira de. A Delação Premiada no Brasil. Rio de Janeiro: Lumen Juris, 2009. p. 54.)

6"Trata-se de instituto importado de outros países, independentemente da diversidade de peculiaridades de cada ordenamento jurídico e dos fundamentos políticos que o justificam. $\mathrm{O}$ fundamento invocado é a confessada falência do Estado para combater a dita 'criminalidade organizada', que é mais produto da omissão dos governantes ao longo dos anos do que propriamente de alguma 'organização' ou 'sofisticação' operacional da delinquência massificada. Na verdade, virou moda falar em crime organizado, organização criminosa e outras expressões semelhantes, para justificar a incompetência e a omissão dos detentores do poder, nos últimos quinze anos, pelo menos. Chega a ser paradoxal que se insista numa propalada sofisticação da delinquência; num país onde impera a improvisação e tudo é desorganizado, como se pode aceitar que só o crime seja organizado?" (BITENCOURT, Cezar Roberto; BUSATO, Paulo César. Comentários à Lei de Organização Criminosa. Lei $n^{\circ}$ 12.850/2013. São Paulo: Saraiva, 2014. p. 116.)

7"Atualmente convive-se em uma sociedade pós-industrial, de ampla produção econômica empresarial e financeira, com técnicas avançadas de comunicação e de informatização, que, de algum modo, trouxe também repercussão sobre os fenômenos delituosos, seu aperfeiçoamento e a forma de enfrentá-los. Aos avanços que decorrer do progresso e das transformações sociais e econômicas acompanham também o ônus, custos que se refletem no direito positivo e nos mecanismos estatais para lidar com os novos eventos, muitas vezes em detrimento de direitos individuais. Portanto, no presente estudo, trata-se mais de reconhecer as consequências de um novo fenômeno, assentindo com a existência de prejuízos no âmbito das relações privadas e públicas, dentre os quais a necessidade de lidar com recentes instrumentos apuratórios como resposta a modernas manifestações da criminalidade. A colaboração processual inclui-se no preço a pagar, nos custos da evolução dos fenômenos sociais." (PEREIRA, Frederico Valdez. Delação premiada - Legitimidade e procedimento. 3. ed. Curitiba: Juruá, 2016. p. 113.)
} 
Essa instrumentalidade da delação premiada para satisfação da sede punitiva pode ser ainda mais evidenciada, quando, reconhecendo ser ela mecanismo da Justiça Criminal Negocial, incluímo-la no contexto de expansão dos espaços de consenso.

Como demonstrou Vinícius Vasconcellos, existe uma relação simbiótica entre a expansão do Direito Penal e a ampliação de espaços de consenso no processo penal, porque a expansão daquele acarreta a "necessidade de instrumentalização de mecanismo funcionalmente célere e eficaz para suprir a demanda por punições rápidas" (VASCONCELLOS, 2015).

Por causa disso, apontam a expansão do Direito Penal como uma das principais causas do triunfo dos mecanismos negociais no processo, já que, para atender às demandas sociais punitivistas, legitimam-se inúmeras reformas sob o argumento da busca por "eficiência" (VASCONCELLOS, 2015).

A justiça consensual, ao retirar o investigado/acusado da posição de resistência à pretensão acusatória, possibilita a concretização antecipada do poder punitivo. No caso da colaboração, mesmo que ainda haja um processo após a homologação do acordo, é certo que há também uma aceleração, porque o réu renuncia sua defesa e ajuda a acusação compartilhando informações e documentos.

Rubens Casara e Antônio Pedro Melchior alertam que a "tirania da urgência" e a hiperaceleração do processo penal representam um risco extremo para o Estado Democrático de Direito:

\footnotetext{
A hiperaceleração conduz a um risco extremo para o Estado Democrático de Direito, principalmente quando não há a compreensão de que existe um tempo do direito que é desvinculado do tempo da sociedade. Nesse contexto, o que se identifica? Uma compulsão por eficiência que transforma o cidadão em consumidor de um genuíno "fast food jurisdicional".

No processo penal - termômetro dos elementos autoritários de um Estado (Goldschmidt) -, a tirania da urgência cumpre papel inegavelmente mais perigoso. Afinal, sendo o ramo mais ideologizado do direito, a eficiência na condenação quase sempre apresenta a "cultura dos direitos e garantias fundamentais como causa de entrave ao funcionamento eficiente do sistema", para usar das palavras de Fauzi Hassan Choukr. As garantias demandam tempo e a frustração da satisfação imediata dos desejos punitivos e das perversões inquisitoriais incomoda aos arautos do punitivismo. (CASARA; MELCHIOR, 2013)
}

Bem por isso, assiste razão a Vinícius Vasconcellos, ao rechaçar a consolidação do "império da economia processual, que, em regra, implementa-se a partir de 'operação de marketing' que propõe a flexibilidade e a funcionalidade frente a morosidade judicial”. Também apontando que, "nesse sentido, inegavelmente a ideia de eficiência integra o lastro teórico primordial da sumarização de procedimentos por meio de mecanismos negociais" (VASCONCELLOS, 2015). 
O jovem processualista aponta ainda que o cenário de mercantilização do processo penal ${ }^{8}$, "em que ilegitimamente direitos fundamentais são transacionados", "se coloca patente como expressão de novas tendências criminológicas em que a gestão dos riscos assume primazia na administração do controle punitivo" (VASCONCELLOS, 2015).

Como obtempera Zygmunt Bauman, ao discorrer sobre as prisões na idade da póscorreção,

(...) há novos e amplos setores da população visados por uma razão ou outra como uma ameaça à ordem social e que sua expulsão forçada do intercâmbio social através da prisão é vista como um método eficiente de neutralizar a ameaça ou acalmar a ansiedade pública provocada por essa ameaça. (BAUMAN, 1999)

A lógica atuarial ajudou o Sistema de Justiça Criminal contemporâneo a adequar-se à nova configuração do Capital. Maurício Dieter inicia sua tese doutoral nos lembrando que "a crítica criminológica do século XX demonstrou que a cada modo de produção correspondem formas de punição adequadas para sua reprodução e desenvolvimento" (DIETER, 2012) 9 . Partindo do consenso de que a neutralização da "underclass ${ }^{10 "}$ se tornou o "point of return" do sistema de justiça criminal estadunidense ${ }^{11}$, Dieter aponta que o desafio passou a

\footnotetext{
${ }^{8}$ Alexandre Morais da Rosa argumenta que a delação premiada implantou um verdadeiro Mercado Judicial Penal. (ROSA, Alexandre Morais da. Para entender a delação premiada pela teoria dos jogos: táticas e estratégias do negócio jurídico / Alexandre Morais da Rosa. - Florianópolis: Emodara, 2018. p. 23.)

9"A pena precisa ser entendida como um fenômeno independente, seja de sua concepção jurídica, seja de seus fins sociais. Nós não negamos que a pena tenha fins sociais específicos, mas negamos que ela possa ser entendida tão somente a partir de seus fins. (...) A pena como tal não existe; existem somente sistemas de punição concretos e práticas penais específicas. O objeto de nossa investigação, portanto, é a pena em suas manifestações específicas, as causas de sua mudança e de ser desenvolvimento, as bases para a escolha de métodos penais específicos em períodos históricos também específicos. A transformação em sistemas penais não pode ser explicada somente pela mudança das demandas da luta contra o crime, embora esta luta faça parte do jogo. Todo sistema de produção tende a descobrir formas punitivas que correspondem às suas relações de produção." (RUSCHE, Georg e KIRCHHEIMER, Otto. Punição e estrutura social / Gerorge Rusche e Otto Kirchheimer, tradução Gizlene Neder. Rio de Janeiro: Editora Revan, 2004. p. 19-20.) E ainda: "As contradições de classes na formação social vinculam o controle do crime às relações de produção na estrutura econômica, determinando a ligação da criminologia com a economia, e de ambas com a política, evitando a distorção positivista que seara a estrutura econômica das superestruturas jurídicas e políticas do Estado, mistificando o conjunto das relações sociais. O processo de criminalização, nos componentes de produção e de aplicação de normas penais, protege seletivamente os interesses das classes dominantes, pré-seleciona os indivíduos estigmatizáveis distribuídos pelas classes e categorias sociais subalternas e, portanto, administra a punição pela posição de classe do autor. (SANTOS, Juarez Cirino dos. A criminologia radical / Juarez Cirino dos Santos. - 3 ed. Curitiba: ICPC: Lumen Juris, 2008. p. 125-126.)

10“"(...) a orientação das práticas punitivas a partir da lógica atuarial é extremamente eficaz, praticamente feita sob medida, para o controle social da "underclass", como desde a década de 80 se denomina o segmento da população que está oficialmente excluído da promessa de mobilidade social mediante regular integração econômica - e, por conta disso, do pleno acesso à cidadania. Espécie de subcategoria dentro da "lower class" e predominantemente formada por negros e hispânicos, a "underclass" constituiria, à vista disso, um grupo social marginal permanente e inevitável que habita as grandes cidades, incapazes de se submeter à exploração pelo trabalho assalariado, isto é, sem a menor possibilidade de acesso às raras posições de emprego remanescentes ou, o que é a mesma coisa, inúteis até mesmo para engrossar as fileiras do exército de reserva." (DIETER, Maurício Stegemann. Política Criminal Atuarial - A Criminologia do fim da história. 2012. 309 f. Tese (Doutorado em Direito) - Programa de Pós-Graduação da Faculdade de Direito, Universidade Federal do Paraná, Curitiba, 2012. p. 248.)
} 
racionalizar os meios para execução deste projeto, de acordo com as exigências da rearticulação capitalista" - sobretudo as vinculadas ao princípio da eficiência. De forma que a lógica atuarial foi a racionalidade mais adequada, sendo "responsável por ajustar as estratégias de controle social às premissas da (a) reestruturação positiva, (b) financeirização do capital e (c) ideologia neoliberal" (DIETER, 2012).

A Política Criminal Atuarial, inspirada pelo "modelo econômico de gestão do risco, promovida pelo princípio da eficiência e instrumentalizada pela lógica atuarial”, seria, então

(...) o uso preferencial da lógica atuarial na fundamentação teórica e prática dos processos de criminalização secundária para fins de controle de grupos sociais considerados de alto risco ou perigosos mediante incapacitação seletiva de seus membros. O objetivo do novo modelo é gerenciar grupos, não punir indivíduos: sua finalidade não é combater o crime - embora saiba se valer dos rótulos populistas, quando necessário - mas identificar, classificar e administrar segmentos sociais indesejáveis na ordem social de maneira mais fluida possível. (DIETER, 2012)

Importante destacar ainda que, segundo Dieter, "a fundação e desenvolvimento da Política Criminal Atuarial não é algo que se explica como parte do desenvolvimento das políticas públicas de segurança no interior do Estado Democrático de Direito", porque inconciliáveis com seus princípios fundamentais:

\begin{abstract}
Além disso, o uso de instrumentos atuariais para fins de incapacitação seletiva tampouco é fenômeno que se compreende como tentativa honesta de busca por eficiência no sistema de justiça criminal, tendo em vista o enorme custo financeiro e social que implica para a pouca redução na criminalidade que levanta como troféu.(DIETER, 2012)
\end{abstract}

Além da hiperaceleração processual penal e da Política Criminal Atuarial, a eficiência também é utilizada para justificar uma emergência investigativa, que justificaria a adoção de mecanismos negociais, como a colaboração premiada:

A situação da emergência investigativa manifesta-se atualmente de forma mais provável na criminalidade organizada ou difusa, tendo em vista as reconhecidas dificuldades probatórias dos tradicionais meios de investigação em alcançar alguma eficiência diante do fenômeno criminal organizado, principalmente por terem sido

\footnotetext{
11“ (...) incapaz de atender com eficiência às novas demandas do Mercado, o sistema de justiça criminal precisou ser reorganizado conforme a nova configuração do Capital. O primeiro passo desta reformulação, por certo, foi trocar a finalidade preferencial do sistema punitivo, sabendo-se que manter o modelo disciplinar do cárcere correcional característico da fase de expansão da sociedade industrial - que conheceu seu apogeu no capitalismo fordista - não era mais uma opção. Oficialmente voltada para a 'underclass', logo se percebeu que não fazia sentido persistir no esforço para ressocializar pessoas que, para começo de conversa, nunca foram formalmente integradas. Contra seus membros, portanto, o argumento em favor da incapacitação era uma decisão lógica, que incentivava a criação e desenvolvimento de novas tecnologias para prevenção do risco mediante vigilância, segregação urbana e, principalmente, contenção, comprometendo-se a penitenciária com a gestão do excesso negativo de trabalhadores no pós-fordismo. Longe de servir à produção e reprodução da subjetividade operária, desistia-se de transformar pobre em proletário via prisionalização; o objetivo da contenção não deveria ser outro que gerenciar os inúteis em uma espécie de quarentena sem justificativa médica. A biopolítica contemporânea se caracteriza, neste horizonte, pela negação da disciplinariedade, dirigindo-se à destruição da subjetividade, tendo em vista que a moralização destas almas não compensa o esforço." (DIETER, Maurício Stegemann. Política Criminal Atuarial - A Criminologia do fim da história. 2012. 309 f. Tese (Doutorado em Direito) - Programa de Pós-Graduação da Faculdade de Direito, Universidade Federal do Paraná, Curitiba, 2012. p. 253-254.)
} 
instrumentos apuratórios moldados sob a perspectiva do ilícito penal clássico, caracterizado pela estrutura individual da lesão cometida por sujeito ativo individual a sujeito passivo também individualizado, levando autoridades responsáveis pela investigação e repressão a condicionar a obtenção de resultados positivos no enfrentamento do crime organizado à adoção de métodos especiais de investigação e inteligência. (DIETER, 2012)

No contexto de expansão do Direito Penal, em que os mecanismos negociais são instrumentais para uma persecução penal "eficiente" sob o "império da economia processual" (VASCONCELLOS, 2015), a Delação Premiada passa a ser tecnologia reinante no exercício do poder punitivo em relação à temida criminalidade organizada.

A delação é fruto de políticas criminais emanadas da ideologia da defesa social e ao mesmo tempo marcadas por lógicas eficientistas, atuariais e emergenciais típicas de teorias contemporâneas da criminalidade ${ }^{12}$.

\section{A DELAÇÃO PREMIADA COMO ESPETÁCULO}

O quadro inconciliável da delação premiada com o regime democrático é ainda mais perturbador, se observarmos o exercício desproporcional, cruel e espetaculoso do poder punitivo dentro da Operação Lava Jato, que, não por acaso, a utilizou de forma exagerada.

A Operação Lava Jato “entrou para a história do país não somente pela proporção dos desvios, mas pela articulação jurídico midiática que respaldou a oposição ao governo federal e gerou consequências à democracia brasileira" (FERNANDES, 2016).

O fato de a Operação envolver desvio de dinheiro da Petrobrás, maior estatal do País, políticos e empresários fizeram do caso "um dinâmico campo de disputa política e econômica" que povoou os noticiários desde que se tornou pública na forma de escândalo ${ }^{13}$.

Com o fomento imprescindível da mídia, empreendeu-se no Brasil com a Operação Lava Jato uma cruzada moralizante da classe política. A luta pela limpeza ética dos espaços

\footnotetext{
12“Não raro, para dar respostas (ainda que meramente formais) às crescentes demandas, o Poder Judiciário recorre a uma concepção política pragmática que faz com que ora se utilize de expedientes técnicos para descontextualizar conflitos e sonegar direitos, ora recorra ao patrimônio gestado nos períodos autoritários da história do Brasil para manutenção da ordem.” (CASARA, Rubens R. R.. Estado pós-democrático: neoobscurantismo e gestão dos indesejáveis / Rubens R. R. Casara. - $1^{\text {a }}$ ed. - Rio de Janeiro: Civilização Brasileira, 2017. p. 127.)

13“'O escândalo político, segundo John B. Thompson (2002, p. 40), é um conjunto de ações ou acontecimentos que implicam certos tipos de transgressões que se tornam conhecidas de sujeitos não participantes do ato e que são suficientemente graves para provocar uma resposta pública." (FERNANDES, Pedro Veríssimo. Arautos da crise - A cobertura da Operação Lava-Jato em Veja e Carta Capital. 2016. 117 f. Dissertação (Mestrado em Comunicação) - Pontifícia Universidade Católica de São Paulo, São Paulo, 2016. p. 8.)
} 
públicos passa à condição de palavra de ordem. É "O Brasil contra a Corrupção" ${ }^{14}$, mesmo que o custo dessa luta sejam direitos fundamentais consagrados pelo regime democrático.

Em que pese represente essa luta eticizante, a Operação teve como um de seus pilares a delação premiada, com a qual, segundo Casara, "desaparece qualquer resquício da superioridade ética que deveria distinguir o Estado do 'criminoso' delator” (CASARA, 2017).

Mas, como se não bastassem os problemas inerentes ao instituto que foi fio condutor das investigações, empreendeu-se uma estarrecedora espetacularização do processo. Nas palavras de Rubens Casara,

(...) o espetáculo é uma construção social, uma relação intersubjetiva mediata por sensações, em especial produzidas por imagens e, por vezes, vinculadas a um enredo. $\mathrm{O}$ espetáculo tornou-se também um regulador das expectativas sociais, na medida em que as imagens produzidas e o enredo desenvolvido passam a condicionar as relações humanas: as pessoas (que são os consumidores do espetáculo e exercem a dupla função de atuar e assistir), influenciam no desenvolvimento e são influenciadas pelo espetáculo. (CASARA, 2015)

Dentre os vários espetáculos que se acumulam na vida das sociedades, "estão em cartaz os “julgamentos penais"”. O fascínio pelo crime, a fé nas penas e certo sadismo fazem do julgamento penal um objeto privilegiado de entretenimento. E isso não é novidade desta quadra histórica. Hannah Arendt descreveu, por exemplo, o cenário de espetacularização do julgamento de Adolf Eichmann (ARENDT, 1999). "O Sistema de Justiça Criminal, com seus atores, mitos e rituais, foi percebido como um locus privilegiado à espetacularização" (CASARA, 2017).

O problema é que "no processo penal voltado para o espetáculo não há espaço para garantir direitos fundamentais", de modo que ele se confronta com a única forma legítima de se conceber o processo em um Estado Democrático de Direito: instrumento de limitação do poder punitivo, por meio da previsão dos princípios, regras e formas que constituem o devido processo e são caminhos necessários para a pena (LOPES JR., 2015).

Se no processo penal democrático, a preocupação é com a reconstrução eticamente possível do fato atribuído ao réu, no processo penal do espetáculo o que ocorre é o primado do enredo sobre o fato. $\mathrm{O}$ enredo, a trama que envolve os personagens do julgamentoespetáculo, é conhecido antes de qualquer atividade das partes e o processo caminha até o final desejado pelo juiz-diretor. O primado do enredo inviabiliza a defesa e o contraditório, que no processo penal do espetáculo não passam de uma farsa, um simulacro. Em nome do "desejo de audiência", as consequências sociais e econômicas das decisões são desconsideradas (para agradar à audiência, informações sigilosas vazam à imprensa, imagens são destruídas e fatos são distorcidos), tragédias acabam transformadas em catástrofes: no processo penal do espetáculo, as consequências produzidas pelo

${ }^{14}$ Título da Reportagem de Capa que tratou do VII Congresso Nacional dos Delegados de Polícia Federal. Revista da Associação Nacional dos Delegados de Polícia Federal. Ano 1. Edição 2. maio.jun.jul. 2017. 
processo, não raro, são piores do que as do fato que se quer punir.(CASARA. 2015)

No processo penal democrático, para concretizar direitos fundamentais, o juiz deve julgar contra a vontade da maioria sempre que isso for necessário para assegurar esses direitos. No processo penal do espetáculo, os direitos e garantias fundamentais são apenas elementos cênicos e, portanto, dispensáveis, bem ao modo do processo penal da Lava Jato (CASARA, 2017)

$\mathrm{O}$ ator jurídico que sucumbe ao espetáculo costuma justificar o afastamento dos direitos e garantias fundamentais como um movimento democrático que vai ao encontro da opinião pública ${ }^{15}$.

É inconteste que numa Operação em que processos nascem "com estardalhaço e power point da 'força tarefa' de Curitiba" (PRONER, 2017), de modo que o oferecimento de uma denúncia é anunciado numa coletiva de imprensa num luxuoso Hotel, há espetacularização. Isso, sem mencionar os vazamentos seletivos de áudios e informações e a "postura messiânica" assumida pelos atores judiciais que "demonizaram a política", os "inquisidores do bem" (PRONER, 2017) - como se isso fosse possível.

A espetacularização e a propagação do caos e da desordem pela mídia se prestam à implementação e justificação de técnicas para neutralizar ou disciplinar grupos específicos segundo o interesse do poder dos dominantes. As estratégias autoritárias de controle à criminalidade são legitimadas na tentativa de extirpação dos demônios, e o respeito às garantias e princípios constitucionais são vistos como caminhos que conduzem ao caos. No caos da criminalidade organizada e da corrupção, o sistema emergencial que implementa a delação encontra fundamento.

Casara pontua ainda que, com a "demonização da política, a população passa a desejar ser gerida por outsiders, pessoas que se apresentem como heróis ou gestores, mas sempre políticos que, ardilosamente, se afirmam não políticos" (CASARA, 2017). Esses salvadores da pátria podem ser messias jurídicos ${ }^{16}$, bélicos ou empreendedores.

\footnotetext{
${ }^{15}$ 'Não se pode ignorar o processo, nada democrático (ou pós-democrático), de formação da opinião pública (que envolve desinformação, manipulação de verdades, deformação da realidade social, recurso ao medo como fator de coesão social, entre outras formas de criar 'consensos'), em especial o papel dos meios de comunicação, que também repercute nos rumos do processo penal voltado para o espetáculo." (CASARA, Rubens R. R.. Estado pós-democrático: neo-obscurantismo e gestão dos indesejáveis / Rubens R. R. Casara. - $1^{\mathrm{a}}$ ed. - Rio de Janeiro: Civilização Brasileira, 2017. p. 165.)

${ }^{16 “(. . .) ~ n a ̃ o ~ r a r o, ~ j u i ́ z e s ~ d e ~ t o d o ~ o ~ B r a s i l ~ p a s s a r a m ~ a ~ p r i o r i z a r ~ a ~ h i p o ́ t e s e ~ q u e ~ i n t e r e s s a ~ a ̀ ~ m i ́ d i a ~ o u ~ a o ~ e s p e t a ́ c u l o ~}$ em detrimento dos fatos que podem ser reconstruídos por meio do processo. No Brasil, a Ação Penal (AP) 470, conhecida como o caso Mensalão e o caso Lava Jato (na realidade, um complexo de casos penais) são exemplos paradigmáticos. Na democracia, os direitos fundamentais de todos (culpados ou inocentes, desejáveis ou não) deveriam ser respeitados, mesmo contra a vontade de maiorias de ocasião. No Estado Pós-Democrático, o Poder
} 
Além da espetacularização e do uso indiscriminado da delação, a Operação revestiuse de especial seletividade. Com o processo de redemocratização após a ditadura, o eixo de atuação repressiva se deslocou do inimigo vermelho para o miserável nocivo (CARVALHO, 2009). Em tempos de Lava Jato, além do considerável incremento do emprego de violência legítima, o eixo da atuação repressiva permanece voltado para os miseráveis, mas também para o inimigo vermelho ${ }^{17}$ :

\begin{abstract}
Em Estados latino-americanos, não atingidos pelo terrorismo, a criação do inimigo passa pelo retorno da demonização das esquerdas e pela criminalização dos movimentos sociais. Os novos golpes contra a democracia, agora travestidos de golpes jurídico-parlamentares, são um sintoma de que há uma nova ofensiva contra as conquistas sociais. Em ambos os casos, há uma inversão ideológica do Direito que passa a macular os direitos humanos ao invés de protegê-los. (PRONER, 2017)
\end{abstract}

Quanto ao uso do Direito Penal como o pó mágico a solucionar todos os problemas, podemos citar a experiência Italiana. Após 25 anos de uma das investigações mais relevantes da história do país, a Operação Mãos Limpas, chegou-se à constatação de que ela não contribuiu para a erradicação da corrupção:

\begin{abstract}
A corrupção mudou parcialmente de forma, mas não, certamente, de intensidade. (...) Esse extraordinário (adjetivo que deve ser entendido em sentido literal, sem acepção positiva ou negativa) período histórico parece não ter deixado, substancialmente, nenhuma herança na luta contra a corrupção na Itália. (...) Infelizmente, não são os super-heróis que podem nos ajudar, mas uma divulgação bem ampla, em todos os níveis, da cultura da legalidade: trata-se, enfim, de um trabalho muito complexo, que precisa de tempo, meios e muita boa vontade. (GIORDANENGO, 2017)
\end{abstract}

Importante destacar que não se está aqui a defender a corrupção, que compromete, corrompe, deteriora e apodrece todo o corpo social, minando as instituições democráticas. Estamos questionando a legitimidade dos instrumentos que têm sido utilizados a pretexto de combatê-la e também o uso do poder punitivo como mecanismo adequado na evitação de um fenômeno social tão complexo como a corrupção.

Concordamos que a corrupção e a confusão entre o público e o privado que acompanham nossa formação histórica e sociológica desde os tempos de colônia devem ser combatidos, até mesmo por questões de governabilidade, mas não à custa de direitos fundamentais imprescindíveis ao regime democrático, e sim reconhecendo a complexidade desse fenômeno social e por meio do uso de uma "política criminal alternativa" ${ }^{18}$.

Judiciário está livre desse dever. O dever desaparece, o verbo modal passa a ser "poder". (CASARA, Rubens R. R.. Estado pós-democrático: neo-obscurantismo e gestão dos indesejáveis / Rubens R. R. Casara. - $1^{a}$ ed. - Rio de Janeiro: Civilização Brasileira, 2017. p. 132.)

${ }^{17}$ Os governos Lula e Dilma, que também adotaram medidas de populismo penal, contribuíram para esse cenário, é importante ressaltar.

18“Impõe-se assim, a necessária distinção programática entre política penal e política criminal, entendendo-se a primeira como uma resposta à questão criminal circunscrita ao âmbito do exercício da função punitiva do Estado 
O controle social da corrupção requer especial atenção e exige maior envolvimento da sociedade nos processos de controle, auxiliando as instâncias oficiais que são imprescindíveis ao controle da Administração Pública, como os Tribunais de Contas, Receita Federal, Poderes Legislativos e Judiciário, Ministério Público, Polícia, dentre outras. Mas deve ser um controle social conjunto, com a participação do povo e o fomento a uma cultura pela legalidade e eticidade nas relações sociais. Creditar a minimização da corrupção unicamente ao direito penal - que no Estado Democrático de Direito tutela subsidiariamente os bens jurídicos - é uma ingenuidade promovida pela criminologia midiática, pelo populismo penal.

Talvez o resultado mais positivo da Operação Lava Jato tenha sido denunciar as ilegalidades e arbitrariedades que sempre imperaram no sistema de justiça criminal. Foi preciso que alguns daqueles que, até pouco tempo, "mereciam" a condição de cidadãos passassem a frequentar as nossas masmorras, para que algumas pessoas conhecessem a realidade a que já estão habituados os clientes usuais do sistema penal.

Mas até aqui pode residir outro problema, se a Operação servir para naturalizar e consagrar ainda mais as ilegalidades e arbitrariedades das quais são vítimas os clientes preferidos do sistema punitivo no Brasil: negros e pobres (SANTOS, 2015). Ao praticá-las contra empresários e políticos, estrategicamente, o Estado reforça o mito de que o sistema penal é igualitário e não é seletivo, dando ares de legitimidade à sua atuação.

Se a Constituição é ignorada para punir a criminalidade de colarinho branco, imaginem para punir aquela praticada pelos pobres, pela massa de excluídos, que adoramos ver enjaulados em "depósitos de lixo" - usando a expressão de Bauman em Vidas Desperdiçadas. Se aplaudem as ilegalidades perpetradas contra Lula, Aécio, Cabral, imaginem aquelas em face de "Amarildos", "Rafaeis Braga".

Da mesma forma, ao recorrer indiscriminadamente a delações e formas ilegítimas de coerção, ajudamos a consolidar essas práticas autoritárias. Em face da criminalidade, uma série de estratégias bélicas que remontam à Inquisição é utilizada; tanto explícita - violência institucional - quanto implicitamente - edição de diplomas legais opostos ao arcabouço

(lei penal e sua aplicação, execução da pena e das medidas de segurança), e entendendo-se a segunda, em sentido amplo, como política de transformação social e institucional. Uma política criminal alternativa é a que escolhe decididamente esta segunda estratégia, extraindo todas as consequências da consciência, cada vez mais clara, dos limites do instrumento penal. Entre todos os instrumentos de política criminal o direito penal é, em última análise, o mais inadequado." (BARATTA, Alessandro. Criminologia Crítica e Crítica do Direito Penal: introdução à sociologia do direito penal / Alessandro Baratta; tradução Juarez Cirino dos Santos. Rio de Janeiro: Editora Revan: Instituto Carioca de Criminologia, 6 ${ }^{\mathrm{a}}$ edição, outubro de 2011. $1^{\mathrm{a}}$ reimpressão, março de 2013. Notas. p. 201). 
axiológico da Constituição. O processo penal da República de Curitiba também alimenta o uso dessas estratégias ${ }^{19}$.

Afirma-se que na Itália, durante a época da operação mãos-limpas, "para cada mafioso ou político corrupto preso, cerca de cem jovens drogaditos ou imigrantes pobres eram detidos" (CARVALHO, 2009).

Depois de lembrar que, na Alemanha Nazista, "o Führer do caso penal (o 'guia' do processo penal, sempre, um inquisidor) podia afastar do processo qualquer direito ou garantia fundamental ao argumento de que essa era a 'vontade do povo', de que era necessário na 'guerra contra a impunidade' ou na luta contra a corrupção'”, Casara adverte:

\begin{abstract}
Vale lembrar, ainda, da ideia de "malignidade do bem": a busca do "bem" se mpre serviu à prática do mal, inclusive o mal radical. O mal nunca é apresentado diretamente como "algo mal". Basta pensar, por exemplo, nas prisões brasileiras que violam tanto a legislação interna quanto os tratados e as convenções internacionais ou na "busca da verdade" que, ao longo da história, foi o argumento a justificar a tortura, as delações ilegítimas e tantas outras violações. (CASARA, 2017)
\end{abstract}

Vinícius Vasconcellos pontua que a "prática que se realiza no Judiciário tem extrapolado em muito o regramento previsto, rompendo em medida com o respeito à legalidade" (VASCONCELLOS, 2017).

Alguns acordos celebrados no âmbito da Operação Lava Jato, os de Paulo Roberto Costa, Joesley Batista e Alberto Youssef, por exemplo, previam benefícios que não estão expressos na lei e até inventavam regimes de cumprimento de pena (BOTTINO, 2016).

Como obtempera Rubens Casara, os direitos e garantias fundamentais foram "vistos como obstáculos aos objetivos repressivos, moralizantes e políticos da Operação"20, o que repercutiu, é claro, na utilização da delação premiada:

(...) não são poucos os relatos de prisões no curso das investigações ou dos processos relacionados à Lava Jato que teriam sido decretadas sem a presença dos requisitos legais e com o objetivo aparente de forçar os investigados ou os réus a fazerem "delações premiadas" (...) Prisões foram utilizadas como forma de coagir pessoas a apresentarem versões que interessavam aos órgãos encarregados da persecução penal. (CASARA, 2017)

\footnotetext{
19“"Esta passagem pela Lava Jato não pretende narrar o trajeto histórico da Operação, mas apenas situar o leitor no impulso que a delação premiada ganhou diante do uso do instituto em face de seus investigados." (ROSA, Alexandre Morais da. Para entender a delação premiada pela teoria dos jogos: táticas e estratégias do negócio jurídico / Alexandre Morais da Rosa. - Florianópolis: Emodara, 2018. p. 24).

20“'As formas processuais, que no Estado Democrático de Direito servem à garantia dos direitos fundamentais, em diversas oportunidades foram desconsideradas. As defesas técnicas dos réus desses processos narram diversos episódios de violações da imparcialidade - da equidistância que os juízes deveriam manter dos interesses em jogo no caso penal -, das regras de competência - vários crimes que deveriam ser julgados em outros juízos criminais acabara, reunidos em uma das varas federais de Curitiba, na qual o juiz passou exclusivamente a se dedicar a eles -, da inviolabilidade das comunicações telefônicas - todo o processo foi marcado pelo 'vazamento' seletivo do teor de conversas telefônicas, algumas das quais com potencial de influenciar na dinâmica político-partidária brasileira -, da vedação da prova ilícita e da cadeia de custódia probatória." (CASARA, Rubens R. R.. Estado pós-democrático: neo-obscurantismo e gestão dos indesejáveis / Rubens R. R. Casara. - $1^{\text {a }}$ ed. - Rio de Janeiro: Civilização Brasileira, 2017. p. 201.)
} 
Além disso, numa relação comovente, a espetacularização potencializa problemas inerentes à delação - como o desequilíbrio entre os atores processuais, a disparidade de armas - e a delação fornece mais ingredientes para o espetáculo:

\begin{abstract}
A delação premiada, que o legislador passou a chamar de "colaboração premiada" para encobrir o desvio ético inerente a toda e qualquer delação, aparece na cena pósdemocrática como um instrumento capaz de potencializar a eficácia punitiva do Estado e, ao mesmo tempo, fornecer novos integrantes ao processo penal transformado em espetáculo. Com a progressiva substituição do desejo de democracia (logo, intimamente ligado ao respeito e às garantias fundamentais) pelo "desejo de audiência" (por sua vez comprometido com a opinião pública), a delação premiada e o vazamento de seu conteúdo acabaram por ser utilizados no decorrer da Operação Lava Jato com a mesma lógica dos efeitos especiais em um filme hollywoodiano. (CASARA, 2017)
\end{abstract}

É o que Alexandre Morais da Rosa chama de "espetáculo da delação, em que a pressão e 'furos de reportagem', bem assim os vieses mercadológicos da tendência dos meios de comunicação de massa movimentam o aparato da Justiça, pautando e pressionando a posição dos jogadores" (ROSA, 2018).

É claro que, a despeito de todos os problemas que podem ser apontados, os atores processuais envolvidos defenderão e tentarão legitimar a delação premiada. Ela é instrumental para a consecução dos objetivos - declarados, ou não - que os movem. Sem ela, a Operação Lava Jato não teria avançado tanto, é óbvio, já que, como observou Alexandre Morais da Rosa, "a ausência de delatores torna a tarefa investigativa complexa, demorada e cara. O atalho proporcionado é valioso" (ROSA, 2018).

A banalização do uso da Delação Premiada fez com que até surgissem advogados "especialistas em Delação Premiada", habituados a realizar o assessoramento e acompanhamento dos acusados na formalização dos acordos, de forma que apontam até mesmo um impacto da delação premiada na defesa criminal clássica, que teria forçado os escritórios de advocacia a adotarem uma sistemática para lidar com as delações.

\title{
5 CONCLUSÕES
}

A análise contextual do resgate do instituto da Delação Premiada no ordenamento jurídico brasileiro, importado devido a influxos mundiais comprometidos com o combate à criminalidade organizada, permite inferir que a Delação Premiada é uma "nova" tecnologia a serviço do poder punitivo, que está em flagrante expansão. Como todos os mecanismos negociais, a Delação importa na renúncia ao direito de defesa e permite o exercício antecipado 
do poder punitivo por abreviar a instrução probatória com a confissão e colaboração do acusado.

E nesse ponto, deseja-se chamar a atenção para o perigo que o instituto da delação premiada pode representar: a desenfreada expansão do poder punitivo, com a mitigação das regras e garantias do processo penal democrático.

Existe uma relação simbiótica entre a expansão do Direito Penal e a ampliação de espaços de consenso no processo penal, porque a expansão daquele acarreta a "necessidade de instrumentalização de mecanismo funcionalmente célere e eficaz para suprir a demanda por punições rápidas” (VASCONCELLOS, 2015).

Mas, como tecnologia do poder punitivo, ela se realiza faticamente porque, mesmo esbarrando na ordem constitucional (VASCONCELLOS, 2015), se desvencilha dessas regras limitadoras por um esforço hermenêutico de relativização de direitos fundamentais por parte da doutrina e pela legitimação de uma política penal autoritária perante a opinião pública. Ela é fruto de políticas criminais emanadas da ideologia da defesa social e ao mesmo tempo marcadas por lógicas eficientistas, atuariais e emergenciais típicas de teorias contemporâneas da criminalidade.

Quando a Delação Premiada é utilizada em processos espetacularizados, o resultado tem sido a desconsideração das garantias processuais e dos direitos fundamentais. A mitigação de garantias e princípios nos afasta do Processo Penal Democrático e amplia o poder penal, sem cumprir a prometida eficiência no combate à criminalidade organizada.

\section{REFERÊNCIAS}

ARENDT, Hannah. Eichmann em Jerusalém. São Paulo: Companhia das Letras, 1999.

BARATTA, Alessandro. Criminologia Crítica e Crítica do Direito Penal: introdução à sociologia do direito penal. Rio de Janeiro: Editora Revan: Instituto Carioca de Criminologia, $6^{\mathrm{a}}$ edição, outubro de 2011. $1^{\mathrm{a}}$ reimpressão, março de 2013.

BATISTA, Vera Malaguti. Introdução crítica à criminologia brasileira. Rio de Janeiro: Revan, 2011.

BAUMAN, Zygmunt. Globalização: As consequências humanas. Rio de Janeiro: Jorge Zahar Ed., 1999.

BITENCOURT, Cezar Roberto; BUSATO, Paulo César. Comentários à Lei de Organização Criminosa. Lei $n^{\circ}$ 12.850/2013. São Paulo: Saraiva, 2014. 
BOTTINO, Thiago. Colaboração Premiada e incentivos à cooperação no processo penal: uma análise crítica dos acordos firmados na "Operação Lava-Jato". Revista Brasileira de Ciências Criminais, São Paulo, v. 24, n. 122, ago. 2016.

CARVALHO, Natália Oliveira de. A Delação Premiada no Brasil. Rio de Janeiro: Lumen Juris, 2009.

CASARA, Rubens R. R.. Estado pós-democrático: neo-obscurantismo e gestão dos indesejáveis. Rio de Janeiro: Civilização Brasileira, 2017.

CASARA, Rubens R. R.. Mitologia Processual penal. São Paulo: Saraiva, 2015.

CASARA, Rubens R. R.. Processo Penal do Espetáculo: Ensaios sobre o poder penal, a dogmática e o autoritarismo na sociedade brasileira. $1^{\mathrm{a}}$ ed. Florianópolis: Empório do Direito Editora, 2015.

CASARA, Rubens R. R.; MELCHIOR, Antonio Pedro. Teoria do processo penal brasileiro Dogmática Crítica e Conceitos Fundamentais. Vol. 1. Rio de Janeiro: Editora Lumen Juris, 2013.

DIETER, Maurício Stegemann. Política Criminal Atuarial - A Criminologia do fim da história. 2012. 309 f. Tese (Doutorado em Direito) - Programa de Pós-Graduação da Faculdade de Direito, Universidade Federal do Paraná, Curitiba, 2012.

FERNANDES, Pedro Veríssimo. Arautos da crise - A cobertura da Operação Lava-Jato em Veja e Carta Capital. 2016. 117 f. Dissertação (Mestrado em Comunicação) - Pontifícia Universidade Católica de São Paulo, São Paulo, 2016.

FOUCAULT, Michel. Vigiar e Punir: nascimento da prisão; tradução de Raquel Ramalhete. 41 ed. Petrópolis, RJ: Vozes, 2013.

GARLAND, David. A cultura do controle: crime e ordem social na sociedade contemporânea / David Garland; [tradução, apresentação e notas André Nascimento]. Rio de Janeiro: Revan, 2008.

GIORDANENGO, Guglielmo. Operação Mãos Limpas - 25 anos. In: Boletim Instituto Brasileiro de Ciências Criminais. Ano 25, nº 295, jun. 2017.

LOPES JR., Aury. Direito Processual Penal. 12 ed. São Paulo: Saraiva, 2015.

PEREIRA, Frederico Valdez. Delação premiada - Legitimidade e procedimento. 3 ed. Curitiba: Juruá, 2016.

PRONER, CAROL. Comentários a uma sentença anunciada - o processo Lula. / Carol Proner et. al. (orgs.). Bauru: Canal 6, 2017.

ROSA, Alexandre Morais da. Para entender a delação premiada pela teoria dos jogos: táticas e estratégias do negócio jurídico. Florianópolis: Emodara, 2018.

RUSCHE, Georg e KIRCHHEIMER, Otto. Punição e estrutura social, tradução Gizlene Neder. Rio de Janeiro: Editora Revan, 2004. 
SANTOS, Bartira Macedo de Miranda. Defesa Social: uma visão crítica. 1 ed. São Paulo: Estúdio Editores.com, 2015. (Coleção para entender direito / organizadores Marcelo Semer, Marcio Sotelo Felippe).

SANTOS, Juarez Cirino dos. A criminologia radical. 3 ed. Curitiba: ICPC: Lumen Juris, 2008.

SEMER, Marcelo. Princípios penais no Estado democrático. 1.ed. São Paulo: Estúdio Editores.com, 2014. (Coleção para entender direito).

VASCONCELLOS, Vinicius Gomes de. Barganha e justiça criminal negocial: análise das tendências de expansão dos espaços de consenso no processo penal brasileiro. São Paulo: IBCCRIM, 2015.

VASCONCELLOS, Vinícius Gomes de. Colaboração Premiada no processo penal. 1 ed. São Paulo: Editora Revista dos Tribunais, 2017.

WACQUANT, Loïc. Punir os pobres: a nova gestão da miséria nos Estados Unidos [A onda punitiva]. $3^{\text {a }}$ ed. Rio de Janeiro: Revan, 2007.

YOUNG, Jock. A Sociedade Excludente: Exclusão social, criminalidade e diferença na modernidade recente. $1^{\text {a }}$ ed. Rio de Janeiro, Revan, 2002.

ZAFFARONI, Eugênio Raúl. Manual de direito penal brasileiro: parte geral / Eugênio Raúl Zaffaroni, José Henrique Pierangeli. - São Paulo: Editora Revista dos Tribunais, 1997. 